\title{
Assessment of Extent and Degree \\ of Thermal Damage to Polymeric Materials in the Three Mile Island Unit 2 Reactor Building
}

\author{
N. J. ALVARES \\ Lawrence Livermore National Laboratory, USA
}

ABSTRACT

This paper describes assumptions and procedures used to perform thermal damage analysis caused by post loss-of-coolant-accident (LOCA) hydrogen deflagration at Three Mile Island Unit 2 Reactor. Examination of available photographic evidence yields data on the extent and range of thermal and burn damage. Thermal damage to susceptible material in accessible regions of the reactor building was distributed in non-uniform patterns. No clear explanation for non-uniformity was found in examined evidence, e.g., burned materials were adjacent to materials that appear similar but were not burned. Because these items wexe in proximity to vertical openings that extend the height of the reactor building, we assume the unburned materials preferentially absorbed water vapor during periods of high, local steam concentration. A control pendant from the polar crane located in the top of the reactor building sustained asymmetric burn damage of decreasing degree from top to bottom. Evidence suggests the polar-crane pendant side that experienced heaviest damage was exposed to intense radiant energy from a transient fire plume in the reactor containment volume. Simple hydrogen-fire-exposure tests and heat transfer calculations appoximate the degree of damage found on inspected materials from the containment building and support for an estimated $8 \%$ pre-fire hydrogen.

\section{INTRODUCTION AND BACKGROUND}

About 10 hours after the 28 March 1979 loss-of-coolant accident began at the Three Mile Island Unit 2 Reactor Building, a hydrogen deflagration of undetermined extent occurred inside the reactor building. Hydrogen was generated as a result of reaction between zirconium nuclear fuel rod cladding and steam produced as the reactor core was uncovered. Ignition of the hydrogen-and-air mixture release after the breach of the reactor-coolant drain tank (RCDT) rupture disk resulted in nominal thermal and overpressure damage to susceptible materials in all accessible regions of TMI-2. Initiation of burn and subsequent termination of induced fires are indicated by data from a variety of pressure and temperature sensors located throughout the containment

This work was performed under the auspices of the U. S. Department of Energy by Lawrence Livermore National Laboratory under contract No. $\mathbf{W}-7405-\mathrm{ENG}-48$ and sections of this paper were originally published in GEND-INF-023, Vol. VI, U.S. Nuclear Regulatory Commission, Washington, D.C. (1983) under DOE Contract No. DE-AC07-76IDO1570. 


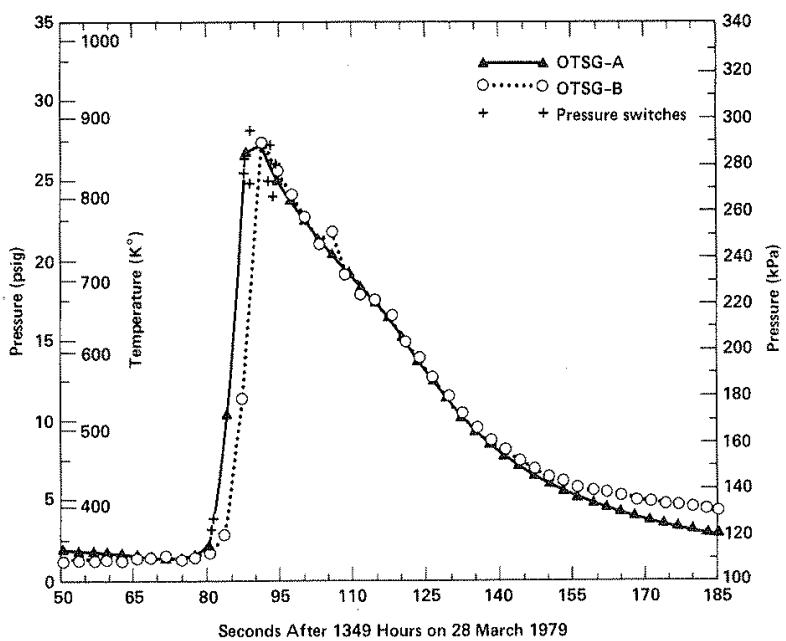

Fig. 1. Pressures recorded during the burn from ors (once-through steam generator) pressure transmitters and pressure switch actuation times. Corresponding average temperature via procedure described in Ref. 1 added to psig scale.

volume. Activation of the building spray system is defined by inflection and increase in the negative slope of interior-pressure-reduction curves (Fig. 1). 1

The hydrogen-in-air concentration $\left[\mathrm{H}_{2}\right]$ was estimated to be approximately 6 to $8 \%$. At this concentration range, propagation of flame is possible upward and horizontally in quiescent conditions, but not downward; however, turbulent conditions, established circulation patterns, and the ambient absolute humidity of the mixture can perturb propagation patterns in ways that are only qualitatively understood.2,3 Assuming uniform mixing of 88 hydrogen-in-air concentration and induction of adequate turbulence in internal circulation flows, flame speeds to $5 \mathrm{~m} / \mathrm{sec}(16 \mathrm{ft} / \mathrm{sec})$ are possible - - even in the presence of saturated steam environments. 4

A cross section of the reactor building (Fig. 2) and plan view of the main $(347-f t)$ operations level (Fig. 3) show the regions of thermal and burn damage. Given that few operational ignition sources were available in the reactor building above the 305-ft level, the time delay to achieve peak overpressure is consistent with an ignition location in the basement. The potential electrical shorting of electrical control systems caused by basement water spillage and the frequency of steam release from the reactor coolant drain-tank pressure-release system supports this assumption.

Thermal damage to fine fuels* indicates general exposure of all susceptible interior surfaces to fire with the exception of random materials including fabric ties of unknown composition, $2 \times 4$ framing lumber on both the 305-ft and 347-ft levels, and various polymeric materials. These unburned items are evident in photographic and video surveys, and were visually reconfirmed by various entry participants. This pattern is reported in several preliminary reports. 5,6 possible mechanisms to prevent thermal

* Fine fuel is defined as a flammable material with high surface-to-volume ratio. 


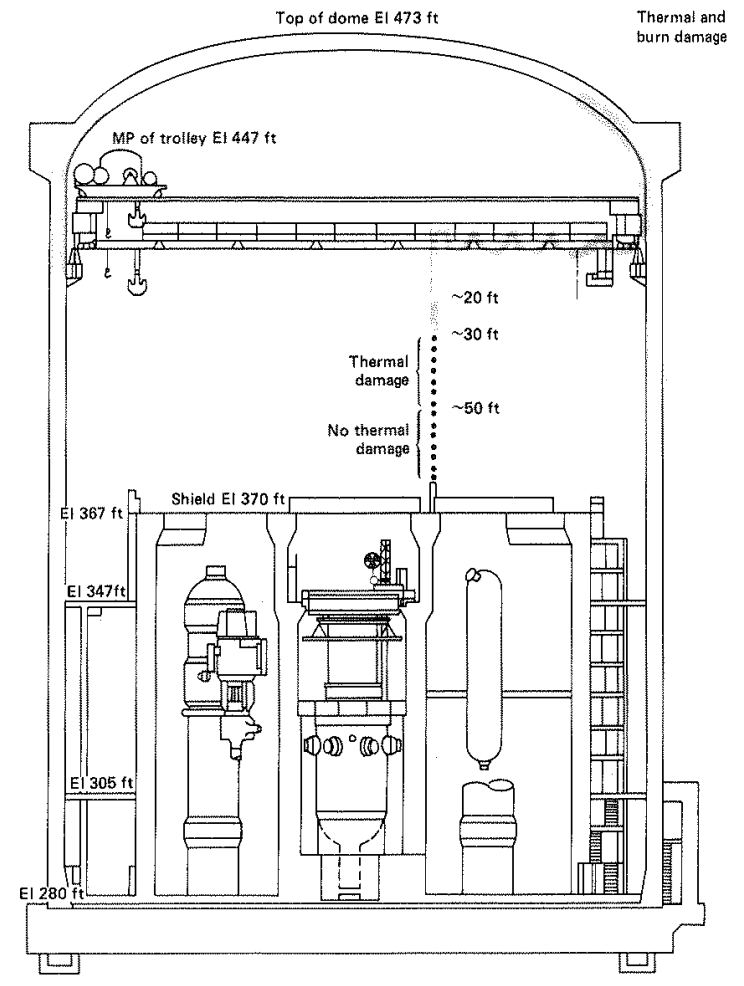

Fig. 2. Cross section of the TMI-2 reactor containment building.

damage to these items include:

1. Preferential absorption of water from saturated atmosphere, requiring greater thermal exposure to produce thermal damage.

2. Direct exposure to high-concentration steam and water vapor, requiring greatex thermal exposure to produce thermal damage.

3. Shielding from thermal radiation by position or geometric obscuration.

4. Shielding from the expanding flame front or convectively driven hot gases by physical obstruction.

Although photographic surveys of internal reactor building vistas, ensembles, items, and surfaces were abundant (approx 600 photos from 29 entries), clarity of burn detail in most photographs was not adequate for diagnostic purposes. However, the extent of thermal damage was defined (Figs, 2 and 3 ) as regions where thermally degraded matexials were located, photographed, and, in some cases, extracted from the reactor building for further examination.

Ignition of a uniformly distributed near-lower-limit mixture of hydrogen in air, spreading from basement ignition sources to the top of the reactor building dome by turbulent propagation modes, occurred in the time period 


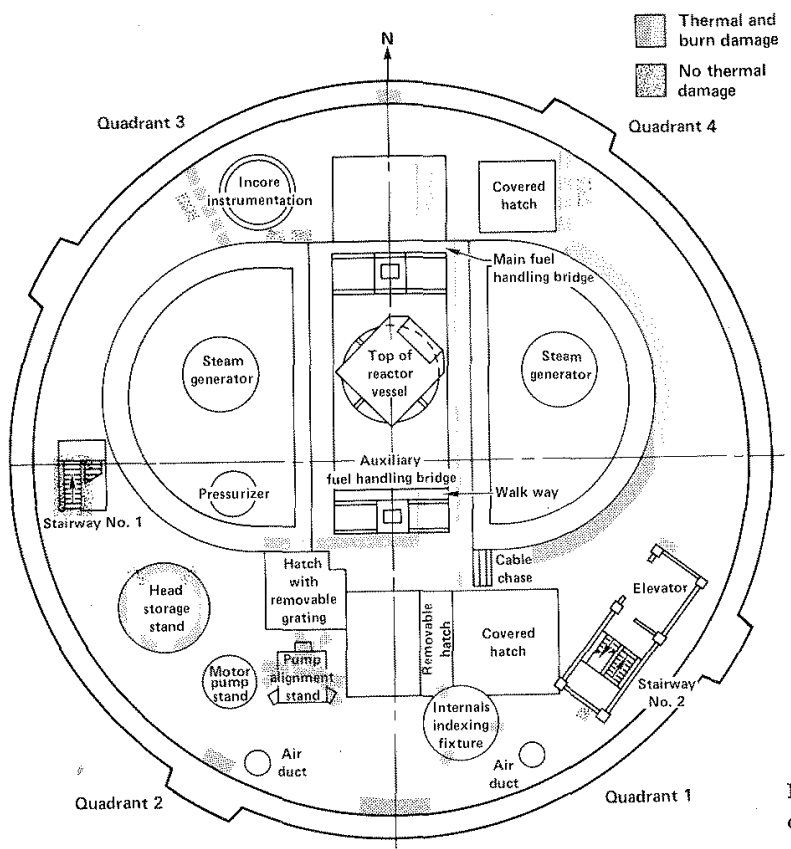

Fig. 3. Thermal and burn damage on the $347-f t$ level.

indicated in Fig. 1. The flame front would have been at an adiabatic flame temperature of about $700^{\circ} \mathrm{C}$ to $800^{\circ} \mathrm{C}$ (approx $1000^{\circ} \mathrm{K}$ ).

Exact paths of flame propagation are undefined. Because of low hydrogen concentration, preferential flame spread was upward in quiescent atmosphere; however, air motion produced by reactor building coolers, steam/hydrogen release from the rupture disk line of the RCDT and natural convection processes caused turbulent flow conditions which greatly modify flame spread rates. The source of major hydrogen release was located near the west open stairway on the undersurface of the 305-ft level plane. Henri and Postma conclude that the primary entry path of the hydrogen-and-steam mixture to the total reactor building above the basement ( $282 \mathrm{ft}$ ) level was through this stairwell. How these gases from the rupture disk line interacted with total ventilation patterns is not known. This may be a moot point since, by the time ignition: occurred, hydrogen in the reactor building was undoubtedly uniformly mixed.

Identification of a specific ignition source is not possible from available documentation; however, two potential basement source-types are considered. (1) Several circuit boxes, instrument racks, meters, and control components were at various locations around D-rings and containment walls at undefined (as built) heights above the basement floor. Thus, failure of circuit components may have been caused by immersion in water. (2) Plant operators who control core and reactor building conditions may have produced ignition arcs from control components perturbed by thermal or mechanical effects of reactor excursion. 7 The inner perimeter of the reactor building basement had no obstructions to block or blind flow of gases outside of the D-ring. Approximately $10 \%$ of the cooled gases from the cooling system plenum $\left(25,000 \mathrm{ft}^{3} / \mathrm{min}\right)$ was distributed to the basement (outside of the $\mathrm{D}$-ring) 
through committed ducting. The only exit paths for these gases were the 4-in. seismic gaps (a space that physically separates each floor level from the reactor building) and the open stairwell that extended from the basement space to the 347-level without barrier. If ignition occurxed at sources away from the open stairwell, the preferred flame propagation would be upward through the seismic gap, and above the 305-ft level, through the grating in the 347-ft level floor. Horizontal spread would occur, but at a slower rate, even during turbulent propagation conditions. Ample evidence exists on the 347-ft level to confirm flame propagation through the seismic gap regions and the floor grating.

At the peak pressure rise of about 28 psig during the hyorogen burn, the adiabatic temperature rise during combustion of 6 to $8 \%$ hydrogen-in-air mixture is about $1000^{\circ} \mathrm{K}$. At this temperature, calculated exposure radiative and convective flux $\left(\dot{q}_{t}\right)$ from an optically thick combustion plume is

$2.2 \mathrm{~W} / \mathrm{cm}^{2}<\dot{q}_{t}<4.5 \mathrm{w} / \mathrm{cm}^{2}$.

For calculational purpose assume emittance of 0.5 , then $\dot{q}_{r}=\varepsilon \sigma \mathrm{T}^{4}=$ $2.8 \mathrm{~W} / \mathrm{cm}^{2}$. This range is approximate because we assume values for combustion plume emittance $(\varepsilon)$ at the limits of the range $0.2<\varepsilon<0.8$. It is quite possible that $\varepsilon$ could be larger for optically thick hydrogen combustion plumes. ${ }^{8}$ Heat transfer coefficient for minimum and maximum convective heat transfer is based on gas velocity $\left(u_{g}\right)$ at the limits of the range:

$3 \mathrm{~m} / \mathrm{sec}<u_{\mathrm{g}}<12 \mathrm{~m} / \mathrm{sec}$.

At $u_{\mathrm{g}}=12 \mathrm{~m} / \mathrm{sec}$ and $\mathrm{L}=1 \mathrm{~m}, \overline{\mathrm{h}}=1.2 \times 10^{3} \mathrm{~K}(\mathrm{Pr})^{1 / 3} \mathrm{Re}^{1 / 2}=2.33 \mathrm{x}$ $10^{-3} \mathrm{~W} / \mathrm{cm}^{2} \mathrm{~K}^{0}, \dot{q}_{\mathrm{C}}=\bar{h} \mathrm{~A}\left(\mathrm{~T}_{\mathrm{S}}-\mathrm{T}_{\infty}\right)=1.6 \mathrm{~W} / \mathrm{cm}^{2}$. Total heat transfer to surface: $\dot{q}_{t}=\dot{q}_{r}+\dot{q}_{c}=4.5 \mathrm{~W} / \mathrm{cm}^{2}$.

\section{EXAMINATION OF TMI MATERIALS}

To estimate the intensity of thermal exposure to damaged materials and to analyze thermal damage patterns, it is necessary to examine their condition and to determine their composition. Photographic evidence is inadequate for such appraisal. We examined materials removed from the reactor building, and recommended removal of additional materials for analysis. We examined the following materials: *

Level 305

1. Polypropylene bucket
Level 347

1. Plywood board

2. Wood from tool box

3. Two radiation signs, probably polyethylene

4. Hemp and polypropylene rope

5. Catalog remains

6. Telephone and associated wire

\section{Polar Crane}

1. Fire extinguisher

2. Hypalon polar-crane pendant jacket control box

*Available July 1983. 


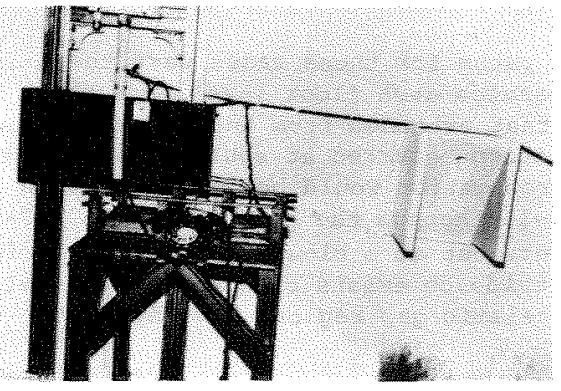

(a) Bel1 telephone at TMI

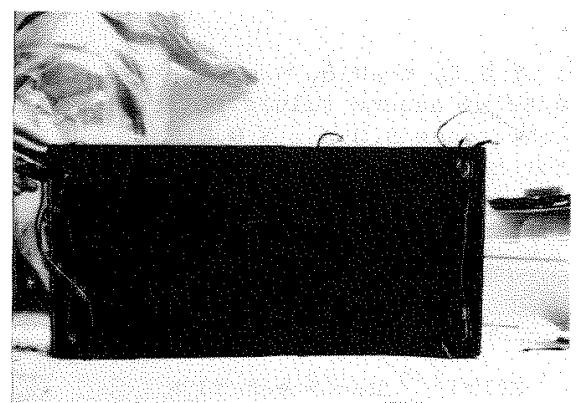

(c) Plywood panel (back)

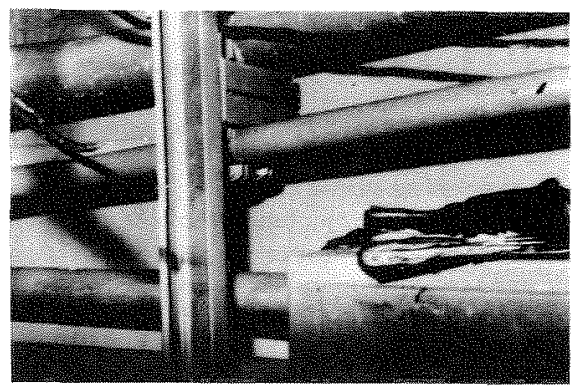

(b) Charred manual on electrical box

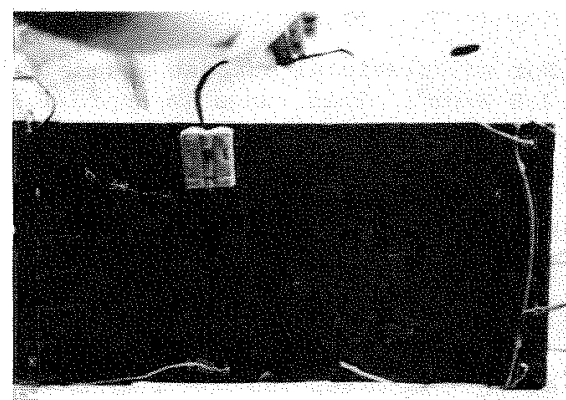

(d) Flywood panel (front)

Fig. 4. Hyärogen-burned in-containment materials extracted from TMI 2 .

These materials retain residual radioactive contamination. Consequently, all examinations were performed under radiologically-safe conditions. Chemical or physical analytical procedures could only be done with contaminated or easily decontaminated instruments. We were unable to locate expendable diagnostic equipment; therefore, our examination of extracted materials was limited to detailed photography and macroscopic observations.

Figure 4 shows photographs of plywood on the reactor building south wall. and remains of an instruction or maintenance manual located on the reactor building north wall, both ignited by fire propagation through the seismic gap and/or radiant exposure from combustion gases in reactor building free volume. In Fig. $4(a)$ note the wires along the wall also exhibit burn trauma. Figures $4(c)$ and $4(d)$ show the front and the rear surface of the plywood panel after it was extracted from the south wall of the reactor building, over the seismic gap. Both sides are charred, as are edges and holes through which wire ties penetrate. Surface char condition indicates the panel ignited to flaming combustion for a short period before self-extinguishing or being quenched by the reactor spray system. Regardiess of the ignition source location, it is apparent that a hydrogen-and-air flame front traversed most of the reactor building volume above (and probably below) the 305-ft level. Duration of this 
propagation was about $12 \mathrm{sec}$. SLow temperature decay before operation of the building spray system ensured thermal exposure to combustible or thermally sensitive surfaces was sufficient to produce thermal damage and/or ignition of these materials, particularly in regions where volume of the combustion plume was optically thick.

\section{THERMAX MEASUREMENTS ON EXEMPLAR MATERIALS}

To augment this analysis, we located exemplar materials generally similar to those removed from the reactor building. Response properties of the exemplar materials were measured in a thermal gravimetric analyzer (TGA) to ascertain the temperature range of thermal degradation and weight-loss rates. Figure 5 shows TGA patterns for ABS (acrylonitrile butadiene styrene), a standard material from the National Bureau of standards (NBS) used as a control for smoke tests. ABS is similar to telephone body material.

Thermograms are obtained by isothermally heating milligram-sized samples of materials, supported on a micro balance, at a constant temperature rate. Weight loss with temperature indicates thermal degradation mode and mechanism. The temperature range of maximum weight loss indicates critical conditions for producing potentially ignitable pyrolyzates. Figure 5 shows that NBS-ABS flammable pyrolyzates are produced in the temperature range of $370^{\circ}$ to $500^{\circ} \mathrm{C}$, leaving about 208 inert materials as residue. These pyrolyzates are flammable which, with an external ignition source, will ignite within this range.

The temperature corresponding to the median of weight loss during the first major weight-loss experience in any polymer can be used to estimate the condition where the rate of thermal destruction is maximum, as in the case of pyrolyzate production. Thus, we can use this temperature to define the time when subject materials are most susceptible to ignition.

Using standard solutions for transient heat conduction in semi-infinite solids with constant thermal properties, it is possible to calculate the time at which a material's surface will attain a specific temperature upon exposure to constant thermal flux levels. Adjustments should be made to account for re-radiation heat losses from exposure surfaces and latent heat processes required to produce pyrolyzates from polymers. With specific surface temperature, exposure heat flux, and defined thermal constants, the time required to reach this temperature is determined by solution of the differential equation for transport heat flow in a semi-infinite solid:

$t=\left(\frac{\pi T s}{2 \dot{q}_{t}}\right)^{2} k \rho c_{p}$

$\dot{q}_{t}=$ total thermal exposure,

$\mathrm{T}_{\mathbf{S}}=$ surface temperature,

$k_{\rho} c_{p}=$ material thermal constants.

Polymexic materials present in most items in common use have thickness of order of $0.2 \mathrm{~cm}$. At this thickness Biot number is less than 1 . In distributed systems, thermal penetration time for such materials is $\Delta x^{2} / \alpha$ and for properties of PVC or PMMa, this time is approx $30 \mathrm{sec}$.

Times calculated using this equation should be short relative to those 


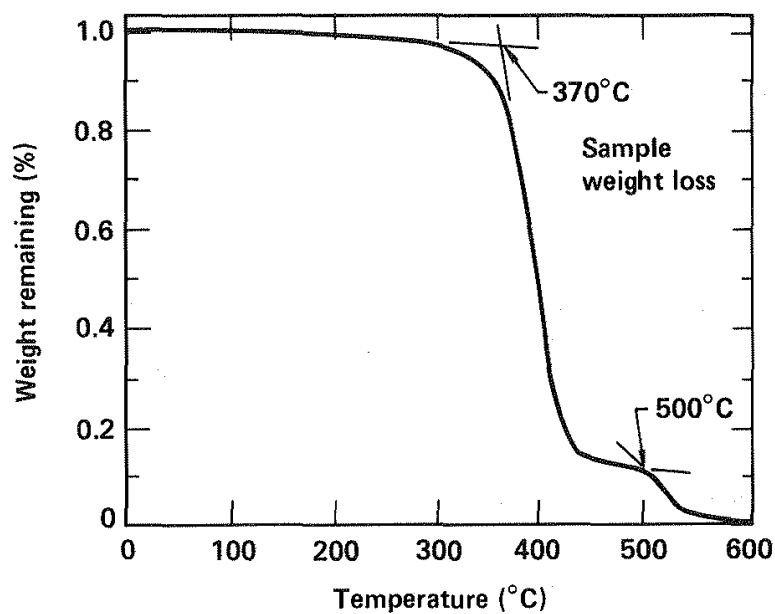

Fig. 5. Thermogram of NBS-ABS. In air, $20 \mathrm{C}$ per min heating rate.

for real materials which experience both thermal and mass convection heat losses. To account for these losses, we adjust $\dot{q}_{t}$ by subtracting from it the surface radiation energy at the specified critical surface temperature and the mass convection losses (the product of surface mass loss and latent heat of pyrolysis). The resultant effective enexgy exposure rate qe replaces $q t$ in Eq. (1), giving a longer time to attain the critical temperature level. Values for time obtained by using both $\dot{q}_{t}$ and $\dot{q}_{e}$ in Eq. (I) bound the time range between exposure of an inert solid and a solid experiencing both re-radiation and latent heat losses. Critical temperature for the three materials is estimated to be $600^{\circ} \mathrm{K}$, and thermal exposure energy is the high value calculated from both convective and radiative exposure during combustion of $8 \%$ hydrogen in air $\left(\dot{q}_{t}=4.5 \mathrm{~W} / \mathrm{cm}^{2}\right)$.

These materials and times to critical weight-loss are

$\begin{array}{lcc}\text { Material } & t_{\mathrm{e}}\left(\dot{q}_{t}\right) & \frac{t_{\mathrm{c}}\left(\dot{q}_{\mathrm{e}}\right)}{\text { Pine wood }} \\ & 5.3 \mathrm{sec} & 9.4 \mathrm{sec} \\ \text { Acrylic } & 32.0 \mathrm{sec} & 54.7 \mathrm{sec} \\ 40.0 \mathrm{sec} & 68.0 \mathrm{sec} .\end{array}$

Times to attain critical temperature conditions in these materials are the same order of duration as those recorded during the hydrogen burn in free volumes of the reactor building. Thus, all susceptible materials exposed to this energy should (and did) experience thermal degradation and/or flaming ignition.

\section{HYDROGEN-FIRE-EXPOSURE TESTS}

Thermal constants of most polymeric materials are defined only for virgin compounds. It is virtually impossible to calculate thermal response properties of commercially available polymers because additives, retardants, and fillers modify fundamental properties; however, simple hydrogen-fire-exposure tests may indicate accident exposure conditions. To assess this possibility, we conducted selected exposure tests on oux exemplar materials using a Meeker burner 
adjusted to a fully premixed burning mode. ${ }^{8}$ size and thickness of these samples were as we found them. The tests were crude and no attempts were made to conform to condition other than to confine time of exposure to the range indicated by TMI-2 pressure measurements. Flow was adjusted to produce a measured flame temperature of $833^{\circ} \mathrm{K}$ (note: during measurement, the 20-mil. thermocouple was incandescent, so measured temperature was substantially lower than actual flame temperature). A simple-copper-slug calorimeter measurement of total thermal flux indicated an exposure flux of $6 \mathrm{w} / \mathrm{cm}^{2}$. This level of flame temperature and thermal flux was within reasonable limits of projected TMI-2 accident measurements and estimated reactor exposure conditions. Thus, resulting data trends should be similar to thermal response variations of materials that suffered hydrogen-flame exposure in the TMI-2 reactor building.

similarity of thermal damage sustained by materials from the reactor building and those used in the small-scale test were encouraging. Both duration and intensity of test thermal exposure is in the range of estimated thermal fluxes extant during the reactor building burn. Note that these are very simplistic tests. No attempt was made to refine temperature or thermal energy measurement. We have no illusion as to the distribution of convective or radiative contribution from the test burner; however, the results give data trends which are intuitively acceptable.

\section{CONCLUSTONS}

On the basis of

1. Photographic and video surveys of the TMI-2 reactor building interior,

2. Visual and photographic analysis of materials extracted from the reactor building,

3. Macro- and micro-experiments with materials of composition generically similar to that of extracted TMI samples, and

4. Calculations using proposed physical conditons and assumed material properties,

the following conclusions are posed:

1. Hydrogen concentration in the reactor building prior to burn is confirmed to be about $8 \%$, as calculated by analyzers of TMI- 2 pressure and temperature records.

2. No defined path for hydrogen propagation has been established.

3. The most probable ignition site for the hydrogen burn is in the basement volume outside of the D-ring: radial location is not defined.

4. Thermal degradation of most susceptible materials on all levels is consistent with direct flame contact from hyarogen fire.

5. The directional character of damage to lower pendant length suggests potential geometric limitation of the hydrogen-fire plume.

6. The total burn pattern of the plywood tack board for the south-wall telephone on the 347-ft level indicates flame propagation through the seismic gap.

7. Lack of themal degradation of random, thermally susceptible materials may result from preferential moisture absorption. Because of the random nature of this evidence, it is not likely that undamaged materials resulted from selective shadowing.

8. Burn pattexns in the reactor building indicate that the dome region above the 406-ft level was uniformly exposed to direct hydrogen flame; the region between the 406-ft level and the top of the D-ring was partially exposed to hydrogen flame (most likely in the south and east quadrants); 
and, the damage on the 305-ft level was geometrically similar to that above the 347-ft level but less severe.

\section{REFERENCES}

I. J. O. Henri and A. K. Postma, Analysis of the Three Mile Island (TMI-2) Hydrogen Burn, Rockwell Internationa1, Rockwell Hanford operations, Energy Systems Group, Richland, WA, RHO-RE-SA-8, 1982.

2. M. Hertzberg, Flammability Eimits and Pressure Development in H - Air Mixtures, Pittsburgh Research Center, Pittsburgh, PA, PRC Report No. 4305 , 1981 .

3. Flame and Detonation Initiation and Propagation in Various Hydrogen-Air Mixtures, with and without Water Spray, Rockwell International, Atomics International Division, Energy Systems Group, Canoga Park, CA, A1-73-29.

4. W. E. Lowry, B. R. Bowman, and B. W. Davis, Final Results of the Hydrogen Igniter Experimental Program, Lawrence Livermore National Laboratory, Livermore, CA, UCRL-53036; U. S. Nuclear Regulatory Commission, NUREG/CR-2486.

5. G. R. Eidem and J. R. Horan, Color Photographs of the Three Mile Island Unit 2 Reactor Containment Building: Vol. 1--Entries 1, 2, 4, 6, 0. 5 . Nuclear Regulator Commission, Washington, DC, GEND 006, 1981.

6. N. J. Alvares, D. G. Beason, and G. R. Eidem, Investigation of Hydrogen Burn Damage in the Three Mile Island Unit 2 Reactor Building, U. $S$. Nuclear Regulatory Commission, Washington, DC, GEND-INE-023 Vol. I, 1982.

7. M. Hertzberg, A. L. Johnson, J. M. Kuchta, and A. L. Furno, "The Spectral Radiance Growth, Flame Temperatures, and Flammability Behavior of LargeScale, Spherical, Combustion Waves," Proceedings of the Sixteenth Symposium (International) on Combustion, The Combustion Institute, Pittsburgh, PA, 1976.

8. B. Lewis and G. von Elbe, Combustion, Flames and Explosions of Gases, 2nd ed., 490, Academic Press, New York, 1961. 